\title{
ENTREVISTA A JESÚS GONZÁLEZ PÉREZ (TRF)
}

1) La RAP, de la que fuiste fundador, ha cumplido sesenta y seis años, que podríamos dividir en tres etapas: una primera desde 1950 hasta 1978, en que se promulgó la Constitución, una segunda que va desde 1978 hasta 1986, año en el que ingresamos en las Comunidades Europeas, y una tercera comprensiva de estos últimos treinta años, en la que hemos vivido como miembros de pleno derecho de la actual Unión Europea. ¿Qué ha representado cada una de ellas para nuestro derecho administrativo? $O$, dicho de otro modo, ¿qué destacarías tú de cada una de ellas desde el punto de vista del derecho administrativo?

La primera etapa comienza con lo que Javier Delgado Barrio ha denominado «década prodigiosa del derecho administrativo español». Pues en estos primeros años que siguieron a la aparición de la $R A P$ se promulgaron tres leyes básicas en la estructuración del Estado de derecho, manifestación de un decidido propósito de sujetar la acción administrativa al ordenamiento jurídico.

\section{-La Ley de Expropiación de 1954}

El anteproyecto se elaboró en la Sección de Administración pública del entonces Instituto de Estudios Políticos, por los miembros de la Sección y por los representantes de cada uno de los Ministerios para cuyas funciones resultaba más necesaria la Ley, que reflejaba, según su Exposición de Motivos, una concepción de la expropiación según la cual debe ser el estatuto legal básico de todas las formas de acción administrativa que impliquen una lesión individualizada de los contenidos económicos del derecho del particular por razones de interés general, y como tal se estructuró, sin perjuicio del obligado respeto a las peculiares características de cada figura en particular.

Si tuviera que destacar una de las novedades de la Ley lo haría de la regulación de la responsabilidad por daños causados por la Administración, por el funcionamiento anormal y normal de los servicios públicos, tan amplia como no se conocía en ningún ordenamiento, lo que un importante sector de la doctrina ha considerado inviable. 


\section{-LA Ley de LA JuRisdicción Contencioso-Administrativa de 1956}

He descrito más de lo debido el proceso de elaboración de esta Ley. Resumidamente en todas las ediciones de mis Comentarios a ella y de la que la sucedió.

La profunda transformación que supuso en nuestra Justicia administrativa, como se reconoció por la generalidad de la doctrina de todo el mundo, fue más tarde discutida y atribuida a la Constitución de 1978.

Existían, por supuesto, normas que constituían obstáculos de una eficaz tutela judicial de los derechos e intereses de los ciudadanos; pero constituyó un paso decisivo en la instauración de la tutela judicial efectiva en el orden administrativo.

Así lo puso de manifiesto el sector más crítico de la legislación que se promulgaba en España en aquella época: el de los españoles exiliados en México. Niceto Alcalá Zamora y Castillo que, en la primitiva versión de su crítica, publicada en el Boletín del Instituto de Derecho Comparado de Méjico $\mathrm{n}^{\circ} 31$ (versión suavizada al publicarse en la recopilación de sus «Estudios Procesales», por Tecnos en 1975), decía: «sería absurdo tildar de totalitario el texto, a causa de las circunstancias en que se ha promulgado, y entrañaría grave error que el día de mañana fuese víctima de uno de esos ciegos bandazos derogatorios a que tanto propende el temperamento político español, salvo las disposiciones de neto sentido discriminatorio señaladas».

Las disposiciones de neto signo discriminatorio fueron mínimas (como la exclusión del control jurisdiccional de los actos dictados en ejercicio de la función de policía sobre la prensa, radio, cinematografía y teatro); otras disposiciones que asimismo contravenían el derecho fundamental a la tutela judicial efectiva eran producto de una tradición legislativa, como la excepción del acto firme y consentido, que por cierto sigue en la Ley actualmente vigente; otras estaban al nivel en que se encontraba la Justicia administrativa (como en orden a las potestades del juez administrativo en la ejecución de las sentencias condenatorias de la Administración), debiendo reconocer que la Ley de 1956 estaba entre las más avanzadas.

Y, sin duda, la más importante de las innovaciones de la nueva Ley fue la especialización de los jueces que habrían de impartir la justicia administrativa, con el sistema de selección por ella instaurada. Quiero dejar constancia aquí del nivel realmente excepcional que tuvieron las primeras oposiciones, no inferior al que tradicionalmente se exigía para cubrir los cuerpos más prestigiosos de la Administración, de las que salieron espléndidos magistrados. Asimismo quiero dejar constancia de lo que supuso 
nuestra $R A P$ para lograr los fines que se perseguían con el nuevo sistema con palabras de uno de los primeros magistrados - Paulino Martín Martín, en el número 150_. El título del artículo era este: "Reflexiones de un ex juez de lo contencioso-administrativo con motivo del cincuentenario de la Revista de Administración Pública». Y el texto, éste:

Puedo decir, sin hipérbole alguna, que quienes fuimos opositores a Magistrados de lo Contencioso-Administrativo en 1959-1960 (primera oposición restringida en toda la historia judicial española), sujetos al programa publicado en el «BOE» el 8 de septiembre de 1958 (las oposiciones se celebraron los primeros meses de 1960), sin la ayuda que nos prestó la REVISTA hubiera sido —en aquel entonces- muy difícil la preparación decorosa e indispensable para enfrentarse al reto que suponía un programa que si bien, desde un punto de vista técnico, respondía muy bien a lo que se pretendía, no por ello dejaba de ser sorpresivo por lo novedoso en razón de su sistemática y profundidad (no en balde a su autor — por lo que se refiere al derecho administrativo, en el que estribaba la dificultad - le venía atribuida ciertamente «una preocupación nueva tendente a dotar al derecho administrativo español de las estructuras técnicas que permitiesen su aplicación y desenvolvimiento efectivos de la vida jurídica»).

Años después, otro magistrado, también de los especialistas (Delgado Barrio, en un trabajo publicado en Poder Judicial, número especial XV, pág. 99), decía:

La situación ha cambiado radicalmente. Las pruebas selectivas que se vienen convocando todos los años están arrojando un resultado muy pobre en número: no se cubren plazas, a pesar de que con acierto se interpretan con gran flexibilidad las reglas relativas al acceso a las pruebas; por ello, el porvenir presumible es sombrío. Las causas determinantes de esta situación son dos: una, general, que no es otra que el bajo nivel de las oposiciones; otra, que el esfuerzo que ello supone no se ve compensado por las perspectivas de ascenso en la carrera judicial que ofrecía el sistema implantado por la Ley de 1956.

\section{-La Ley de Procedimiento Administrativo de 1958}

La Ley de Procedimiento de 1958 trató de poner fin a la diversidad de disposiciones de distinto rango y diferente regulación de aspectos fundamentales del procedimiento. Pero una ley de procedimiento admi- 
nistrativo no puede ser una ley que contenga todos los procedimientos administrativos, porque esto sería tanto como una codificación administrativa que es un ideal inaccesible: el legislador, al regular una actuación administrativa, puede adoptar uno de estos dos criterios: establecer el cauce formal que ha de seguirse determinando en qué orden y en qué momento han de realizarse todos y cada uno los trámites que integran el procedimiento de que se trata, o dejar al instructor en libertad para seguir el procedimiento que estime idóneo, atendiendo a las ideas de simplicidad, eficacia y garantía.

Entonces, ¿cuál debe ser el contenido de una ley general de procedimiento? Hay, por cierto, una serie de normas de la Ley de Procedimiento Administrativo que deben tener - y realmente tienen - una aplicación general, cualquiera que fuera el tipo de procedimiento. Son normas que regulan aspectos, incluso estrictamente procedimentales, respecto de los que no tiene relevancia el objeto sobre el que se incida el procedimiento. Pensemos en las normas reguladoras de la actividad de ordenación. No tiene sentido que los actos por ellas regulados deban estar sujetos a régimen distinto en función de la materia. Los actos de notificación, comunicación entre órganos, certificación, desglose de documentos y todos los estrictos de ordenación deben ser idénticos y con una sola regulación: las normas sobre ellos de una ley de procedimiento administrativo serán aplicables cualquiera que sea el procedimiento.

Pero, en general, la función de una ley de procedimiento administrativo será muy distinta según la categoría de los procedimientos.

Respecto de los procedimientos no formalizados, una ley general de procedimiento administrativo ha de contener la regulación de las exigencias mínimas a las que en todo caso ha de ajustarse aquel al que corresponde la instrucción del procedimiento, así como el instrumental jurídico que necesita para realizar la función administrativa encomendada. La ley general regulará - y lo hará detalladamente- cada uno de los instrumentos que pueden utilizarse (v. gr., alegaciones, prueba, información pública, audiencia y vista). Y el instructor utilizará en cada caso aquellos que sean necesarios, prescindiendo de todo trámite inútil. Reducido al mínimo el principio de preclusión, se realizarán sólo los que sean indispensables para cumplir con la debida eficacia los fines perseguidos.

Y respecto de los formalizados se impone otra elemental distinción. Porque si bien la naturaleza de la función ejercitada y la materia sobre la que recae condicionan decisivamente el cauce formal al que debe ajustarse la actividad administrativa, esto es así en líneas generales; pero hay procedimientos que no están condicionados por el objeto. No influ- 
ye para nada la materia sobre la que puedan versar. El ejemplo típico lo constituyen los procedimientos de revisión de los actos administrativos. Los trámites que han de seguirse para la decisión de un recurso administrativo no variarán en absoluto por el hecho de que el acto objeto de impugnación sea una licencia de construcción o el acto de destitución de un funcionario. Cuando de lo que se trata es de verificar la legalidad de un acto, su conformidad con el ordenamiento jurídico, es irrelevante su contenido. Como también lo es en los procedimientos sancionadores: podrá variar, según la materia, el cuadro de las infracciones y el de las sanciones aplicables a cada una de las infracciones tipificadas por la ley. Pero el procedimiento para imponer la sanción debe ser el mismo, en cuanto viene informado por las garantías constitucionales frente al ejercicio de la potestad sancionadora de la Administración, que deben ser las mismas que la Constitución establece frente al ejercicio de la potestad penal.

Y esto es lo que hizo la Ley de 1958.

2. La segunda etapa se caracterizó por la adaptación del ordenamiento a la nueva Constitución y el tránsito del Estado nacional al Estado de las nacionalidades.

La purificación de la normativa vigente del anterior régimen se realizó en buena parte por vía jurisdiccional de los distintos órdenes jurisdiccionales al considerar nulas las leyes contrarias a la Constitución por la inconstitucionalidad sobrevenida; ya que carecían de jurisdicción para enjuiciar la posible constitucionalidad de las dictadas después de entrar en vigor la Constitución. Pero lógicamente la vía normal fue la sustitución de las leyes anteriores por otras que desarrollaron principios constitucionales, aunque hubiera sido posible y conveniente en muchos casos la simple modificación, como recomendaba ALCALÁ-ZAMORA y CASTILLo en la crítica a la Ley de la Jurisdicción Contencioso-Administrativa, a que antes me referí. Y así se intentó. Siendo ministro de Justicia Íñigo Cavero encargó a la Comisión General de Codificación que propusieran las modificaciones que estimaran que debían introducirse en la Ley de 1956, a fin de eliminar los preceptos que contravinieran la Constitución y modificar los que pudieran mejorar el sistema. Y dentro de la Sección de Administración pública se designó una comisión al efecto presidida por Villar Palasí y formada, de una parte, por magistrados de los llamados «especialistas» y, por otra, por catedráticos de derecho administrativo, que ejercían la abogacía (creo que estaban Enterría, Martín-Retortillo y Fernando Garrido conmigo). Terminado nuestro trabajo, que cumplía los objetivos propuestos, también terminó la etapa de ministro de Íñigo 
Cavero. Y también terminó la idea de mantener una ley a pesar del momento en el que había nacido.

La irrupción de las comunidades autónomas en la vida política fue otro de los acontecimientos de la vida política que caracteriza esta etapa. Las imprecisiones de la normativa del Título VIII de la Constitución, fruto del llamado "consenso", la falta de vigor en las instituciones del Estado, la impunidad de algunas Autonomías a pesar de negarse abiertamente a cumplir las sentencias de los órganos del Poder Judicial, han dado lugar a una situación que excede del derecho administrativo y hasta del derecho.

Cuando estudiaba el derecho administrativo regulador de algunas materias en un Estado federal y veía que las diferencias entre las leyes de los Estados miembros radicaban únicamente en la concepción que sobre esa materia tenía el profesor o profesores a los que se había encargado el anteproyecto que, sin apenas modificaciones legislativas, se convertía en ley, no podía comprenderlo.

Y esto es lo que más o menos ha ocurrido al ejercer las funciones legislativas las comunidades autónomas en materias que nada tienen que ver con lo que es el espíritu de un pueblo y se tratase de necesidades comunes con las fórmulas técnicamente más adecuadas.

3. En la tercera etapa dominarán las prescripciones para resolver del mejor modo posible los problemas planteados por la pluralidad de competencias: las de los órganos de la Unión Europea y la de los distintos Estados de la Unión.

2) En tu obra ha destacado siempre la preocupación por las garantías del ciudadano frente a los poderes públicos. ¿Qué piensas tú respecto de la pluralidad de ordenamientos jurídicos —estatal, autonómicos, europeosque rigen hoy nuestra vida cotidiana y de la pluralidad de Tribunales nacionales (Tribunal Supremo y Tribunales Superiores de Justicia, Juzgados de lo Contencioso-Administrativo) y supranacionales (Luxemburgo y Estrasburgo) a los que hoy podemos acudir en defensa de nuestros derechos? ¿Son positivas o negativas sus consecuencias desde el punto de vista del ciudadano?

Creo que mi opinión sobre la pluralidad de ordenamientos ha quedado adelantada al contestar a la pregunta anterior. Sus consecuencias son para mí negativas desde el punto de vista del ciudadano. Pero con todos sus defectos ahí están. De aquí la importancia de los tribunales, si no para eliminarlos, al menos para paliarlos. Con lo que paso a tratar la segunda de las cuestiones que me planteas. 
Aunque la pluralidad de tribunales que ejercen la jurisdicción en el orden contencioso-administrativo parece excesiva, creo que está justificada por la diversidad de las materias de los conflictos que han de resolver, la distinta naturaleza de los sujetos que los provocan y la complejidad de la organización de la Administración.

Pero lo que es incuestionable es la compleja y confusa distribución de las competencias, lo que podría simplificarse eliminando alguna de esas largas listas de las competencias de los distintos órganos, utilizando cláusulas generales.

Respecto de los tribunales supranacionales, el que propiamente está instituido como garantía supranacional de los derechos de los ciudadanos es el de Estrasburgo. Pero, por su propia naturaleza, adolece de importantes deficiencias para prestar una tutela eficaz, aunque en ultimísima instancia, a los derechos fundamentales y libertades públicas.

-El requisito de agotar las vías internas. La necesidad de agotar las vías de recurso internas da lugar a que cuando pueda llegarse al tribunal, ya no tiene sentido la tutela, porque la lesión al derecho fundamental o libertad pública está más que consumada. De aquí que el artículo 41 del Convenio establezca que si el tribunal declara que ha habido violación y el derecho interno del Estado en que se ha cometido «solo permite de manera imperfecta reparar las consecuencias de dicha violación, el tribunal concederá a la parte perjudicada, si así procede, una satisfacción equitativa». Este requisito se agrava cuando, como ocurre en el ordenamiento español, entre las vías de recurso internas figura una tan excepcional como es el amparo. En consecuencia, antes de acudir a éste, una vez agotados todos los recursos admisibles ante los órganos del Poder Judicial, lo que supone varios años, muchos años en nuestra Justicia actual, será necesario el recurso ante el Tribunal Constitucional.

- Agotadas las vías internas, queda abierta la del proceso ante el Tribunal de Estrasburgo. Y aunque la tramitación, como la del proceso administrativo ante los tribunales españoles, no es complicada, tampoco puede decirse que las sentencias lleguen en un «plazo razonable», que es una de las exigencias del derecho a una causa equitativa, tal y como lo consagra el artículo $6^{\circ}$ del Convenio de Roma.

- Y, después de esto, ¿qué es lo que dice la sentencia? El artículo 46 del Convenio de Roma dispone que «las Altas Partes Contratantes se comprometen a acatar las sentencias definitivas del tribunal en los litigios en que sean partes». Pero si lograr la ejecución de la sentencia de un tribunal estatal cuando es condenatoria de un órgano de otro Poder del Estado es una tarea llena de dificultades, ¿qué dificultades no encontrará la ejecución de una sentencia de un tribunal no estatal cuando, además 
de las barreras interiores entre Poderes, se levanta la del Estado frente a un tribunal exterior? Pero, además, es que los términos de las sentencias no pueden ser menos congruentes con lo que es el ejercicio del «poder de juzgar y hacer ejecutar lo juzgado», que es lo que es el Poder Judicial. Si una sentencia, toda sentencia, es algo más que una operación mental o juicio lógico, es un acto de voluntad del juez y, por tanto, del Poder, un mandato de ineludible observancia, un mandato que proviene del órgano jurisdiccional, y, por tanto, del Estado, ¿en nombre de qué Poder dicta sentencias el Tribunal Europeo? ¿Qué fuerza coactiva tiene detrás para llevar a puro y debido efecto sus fallos? El poder que proviene de un tratado internacional entre Estados soberanos. Pero las sentencias del Tribunal Europeo no son un mandato. No mandan. La fórmula que emplean es que el Tribunal dice, declara; no ordena, no condena. El tenor literal de su parte dispositiva suele ser: «Por estos motivos el Tribunal dice por seis votos contra uno, que ha habido violación del artículo $6^{\circ} .1$ del Convenio».

3) Has analizado con minuciosidad las sucesivas Leyes de Procedimiento Administrativo, de 1958 y de 1992 y, sin duda, también las novísimas Leyes 39 y 40 de 1 de octubre de 2015 sobre el Procedimiento Administrativo Común y el Régimen Jurídico del Sector Público. ¿Crees que estas últimas han supuesto algún avance?

La Ley de Procedimiento Administrativo, como te he recordado al contestar la pregunta primera, fue una de las de la llamada «década prodigiosa del derecho administrativo español», que tanto significó en la instauración de un Estado de derecho. Pero ha sido una Ley desgraciada. Todas las que la han sucedido, salvo en algunos aspectos concretos, han supuesto un paso atrás.

La Ley de Régimen Jurídico de las Administraciones Públicas y del Procedimiento Administrativo Común, de 26 de noviembre de 1992, que la derogó, ha sido la Ley que ha recibido críticas más duras desde que me dedico a este oficio. Recuerdo que se llegó a decir de ella que es una de esas leyes que se hacen simplemente porque se tienen que hacer; «que no sirven nada más que para decir que se ha cumplido con un precepto constitucional» (MUÑOZ MACHADO); «una catástrofe sin paliativos» y que aducir como fundamento que la Ley que va a sustituir fue promulgada durante la dictadura tendría el mismo sentido que destruir los pantanos porque fueron hechos por el mismo dictador (PARADA); que sus novedades son en su mayoría innecesarias y de pura retórica (S. MARTín-RETORTILLO); y que «lo mejor que se podía hacer era comenzar urgentemente a 
elaborar una Ley de modificación parcial, ya que no hay ninguna razón para esperar que sus inevitables efectos negativos se produzcan y se pudran» (GARCÍA DE ENTERRía).

A pesar de las críticas y de las reiteradas peticiones de reforma, ésta no llegó hasta siete años después con la Ley 4/1999, por un Gobierno de signo distinto, que no se enfrentó con los grandes problemas que la Ley de 1992 había dejado pendientes y, por lo general, se limitó a incorporar doctrina jurisprudencial que ya había esclarecido las dudas planteadas por la normativa anterior.

Y esta lamentable evolución legislativa culminó con la promulgación de las Leyes 39 y 40 de 2015, de 1 de octubre, del Procedimiento Administrativo Común de las Administraciones públicas, y de Régimen Jurídico del Sector Público.

El título de una de las críticas de estas dos Leyes que han aparecido no puede ser más expresivo de lo que significan en nuestro ordenamiento jurídico: «una reforma precipitada o la desarticulación gratuita del régimen jurídico de las Administraciones públicas», en cuanto se deroga y divide caprichosamente su contenido en dos textos legales, que mezclan materias distintas con escaso orden (SÁnchez Morón). Y lo grave es que se ultimó urgentemente su elaboración haciendo caso omiso de la crítica razonadísima de los dictámenes del Consejo de Estado.

4) ¿Qué piensas de la evolución de la justicia administrativa, tú que fuiste uno de los autores de la LJ 1956?

Precisamente el artículo que publiqué en el número de la Revista conmemorativo de su 50 aniversario estuvo dedicado a la evolución de nuestra legislación contencioso-administrativa hasta la Ley 29/1998 de 13 de julio, que sustituyó a la de 1956. Aunque la trascendencia de la Constitución en la regulación de la Ley y algunas de las críticas de la derogada fueron desorbitadas, la suerte de aquella Ley no fue ni mucho menos la de la Ley de Procedimiento Administrativo. Se abandonó la posición del ministro Cavero y surgieron unos anteproyectos que, por lo general, partían de lo que venía a ser un texto refundido de la Ley con la normativa de la propuesta que se hizo al ministro Cavero.

La normativa de la Ley que no había quedado derogada por la jurisprudencia, interpretándola «según la realidad social del tiempo en que había de ser aplicada», lo fue por la nueva, acogida con reservas. Como dijo Enterría, el estilo de la nueva no resulta comparable al de la Ley sustituida, un ejemplo de elegantia iuris, de concisión y de eficacia organizadora. 
Pero mal que bien lo cierto es que prestó tutela judicial efectiva en este orden jurisdiccional.

El grave problema que tenía y, aunque algo aliviado últimamente, tiene la justicia administrativa es la lentitud. No podemos decir que nuestro proceso administrativo no incurre en dilaciones indebidas. Lo que, entre otras consecuencias, ha dado lugar a la multiplicación de órganos jurisdiccionales con la consiguiente confusión en la delimitación de las competencias. Y al abuso de formalismo para reducir el número de las que han de tramitarse hasta el final para evitar el enjuiciamiento de pretensiones que podrían estar bien fundadas.

La última reforma de la legislación procesal se ha producido por la LO 7/2015, que modifica la LOPJ y en su disposición final tercera, el régimen del recurso de casación en el proceso administrativo. Indudablemente introduce modificaciones positivas como la unificación de la casación, la eliminación de la exigencia de tipificar las infracciones en que se funda el recurso en los motivos tasados por la Ley, que ha dado lugar a buen número de inadmisibilidades y la facultad que se reconoce a la Sala de Gobierno del Tribunal Supremo de determinar la extensión máxima de los escritos y condiciones extrínsecas de los escritos de interposición y oposición de los recursos.

Pero, sin duda, la novedad más importante radica en reconocer a la Sala la facultad de estimar si el recurso presenta interés casacional para la formación de jurisprudencia. De todos los recursos que se interpongan, la Sala elegirá el número de los que van a resolver. De cómo ejercerá esta facultad dependerá que constituya una forma más de aumentar los formalismos que padecemos. $\mathrm{O}$ que realmente sirva para que la casación se limite a cumplir su finalidad propia de la formación de jurisprudencia. Yo creo que la interpretación será la adecuada, como ha sido la que se ha venido haciendo al interpretar el «interés casacional» en los procesos de una cuantía indeterminada desde la reforma de 2009.

5) ¿Y de la justicia constitucional, a la que tú dedicaste el primer libro sobre el TC?

El Tribunal Constitucional adolece de un mal de nacimiento: el sistema de selección de los magistrados que lo integran. Si la politización es un mal que padece la Justicia, en el Constitucional la gravedad es innata. Como la Constitución es lo que en cada caso diga el Tribunal Constitucional, y la ambigüedad es general en la regulación de las cuestiones polémicas de la Constitución, ésta será distinta según los magistrados que, en cada caso, decidan y el momento en que decidan. Y aunque no 
exista ambigüedad, la politización es la que domina. Recordemos las filigranas que tuvo que hacer la mayoría que decidió el recurso contra la reforma del Estatuto de Cataluña para no declarar inconstitucionales algunos de sus artículos.

Desde otra perspectiva, estamos contemplando todavía el espectáculo que nos está brindando el Tribunal con la tramitación del recurso interpuesto contra la ley reguladora del aborto.

Pero voy a referirme únicamente al Tribunal como protector de los derechos fundamentales. Estoy tan convencido de que el amparo no constituye una garantía de los derechos fundamentales que en mi intervención en la Academia de Ciencias Morales y Políticas del día 22 de noviembre de 2006 me atreví a proponer su desaparición. Y no he sido el único. Es más, en el proceso constituyente se formularon enmiendas para «interrumpir el embarazo». Como la de nuestro compañero Lorenzo Martín-Retortillo, por entender que:

- La extensión de la jurisdicción contencioso-administrativa, sin restricciones, cubriría con creces la necesidad de un control de la actuación de los Poderes públicos, como sucede en otros países.

- Tal atribución supondría una carga tal para el Tribunal Constitucional, que le dificultaría ejercer su jurisdicción en aquellas materias que le son propias, $\mathrm{y}$

-en consecuencia, cree preferible potenciar la jurisdicción ordinaria, superar la inseguridad, la duración, incluso la carestía de los pleitos y buscar fórmulas enérgicas de protección jurisdiccional.

Y, además, para evitar los conflictos que dan lugar a la existencia de dos Tribunales Supremos, como ha puesto de manifiesto la realidad, que ha motivado lo que Rafael Mendizábal ha llamado la "guerra de los jueces», por la «rebelión de los jueces», de los auténticos, de los del Poder Judicial contra sentencias de los otros, los del Tribunal Constitucional, que al iniciar sus funciones quisieron dar lecciones a los que consideraban «herederos del antiguo régimen».

Porque el «amparo» tal y como se concibió pretendía constituir una garantía última de los derechos fundamentales. Para llegar a él, hace falta: si la violación está originada «por disposiciones, actos jurídicos o simple vía de hecho» de órganos políticos o administrativos, haber agotado la vía jurisdiccional procedente (art. 43.1 LOTC); si la violación tenía su origen inmediato y directo en un acto u omisión de un órgano judicial, agotar todos los recursos utilizables en la vía respectiva [art. 44.1.a), LOTC]. 
Bastaría tener en cuenta el tiempo que requiere agotar la vía judicial y los recursos utilizables ante el orden jurisdiccional correspondiente para demostrar la ineficacia de lo que pretende ser una protección de los derechos fundamentales de la persona.

No obstante, ante lo atrayente de la novedad de la institución, fueron muchos los que acudieron al tribunal recién creado con la esperanza de que se les hiciera justicia cuando ésta no la habían obtenido ante los jueces ordinarios, o cuando eran éstos los que la habían conculcado en los procesos para los que tenían jurisdicción. Y más cuando se comprobó que, al empezar de nuevo y no tener el atasco de recursos pendientes, se lograba sentencia en plazos bastante razonables, y hasta que fuera frecuentemente favorable, sobre todo cuando el supuesto violador de los derechos había sido un juez o tribunal, y que aquel primer tribunal quería dar lección de administrar justicia a una Judicatura heredada del antiguo régimen, para demostrar cómo se hacía justicia en el Estado social y democrático de derecho. Frente a la rigidez y formalismo que imperaba en los recursos judiciales se hacía gala de flexibilidad en el acceso al amparo.

Naturalmente, ocurrió lo que tenía que ocurrir. Y llegó un momento en que no había forma de convencer a un cliente que había agotado todos los recursos ante los tribunales en su demanda de justicia, de que no podía ser más descabellado acudir al amparo previsto para supuestos muy concretos, que no se daban en su caso. Siempre conocían algún amigo que había logrado ganar un amparo ante el Tribunal Constitucional.

Y éste se vio desbordado con amparos que no tenían razón de ser. Pero también con algunos muy fundamentados. El resultado fue que el tan vilipendiado formalismo de los jueces fue ampliamente rebasado por el Tribunal Constitucional. Las cifras de inadmisibilidades fueron espeluznantes. No puede ser más aleccionador el examen de la evolución de la jurisprudencia constitucional desde aquellas primeras sentencias hasta las de hoy. 